\title{
Making a difference: Doing leadership research that matters
}

\author{
Dennis Tourish \\ University of Sussex Business School, Jubilee Building, Falmer, Brighton BN1 9RH \\ Corresponding author. Email: d.j.tourish@sussex.ac.uk
}

(Received 2 December 2018; accepted 26 January 2019; first published online 22 March 2019)

\begin{abstract}
Leadership research largely ignores the really big issues facing our species, such as climate change, the now rapid growth of new technologies that are already transforming the world of work, and the possibility that an insufficiently reformed banking system will inflict a worse crisis on us than it did in 2008 . We also have a proliferation of leadership constructs that often look remarkably like those they are trying to replace. There is much heat but little illumination. The dominant methodologies that the field employs are part of a wider crisis in management studies where many of our claimed results are invalid and/or unreliable, unreproducible and offer little guidance for practice. I conclude that radical changes are needed if we are to play a serious role in improving the world in which we live. Let's take Ken Parry's lead, and make a difference.
\end{abstract}

Keywords: research methods; leadership; privacy and ethics; transformational leadership

\section{The Neglect of Important Topics}

Most of the leadership research that is currently published, particularly in 'leading' journals, ignores the really important issues that confront our world. In part, this reflects an unhealthy preoccupation with 'developing theory' for its own sake rather than on making a positive difference. These problems, I argue, are compounded by the bias of our journals that favours the publication of only positive results, and a cynical use of flawed methods that enables researchers to deliver them. This is facilitated by the study of trivial issues, since more complex questions are less easily shoehorned into the hypothetico-deductive models favoured by elite journals.

As an example, consider what is probably the most important problem now facing our species. Unless, dear reader, your name is Donald J. Trump it should be clear by now that climate change poses an existential threat to the environment, biodiversity and our own species. Yet when I searched The Leadership Quarterly using the term 'climate change' I found no hits in the title, abstract or keywords of any papers. Full disclosure: I edit the journal Leadership, and we have published nothing on climate change either. This neglect is hard to square with the urgency of the problem. The United Nations Intergovernmental Panel on Climate Change (2018) published a report which outlined the scale of the crisis that is already upon us. It suggested that we have at most 12 years to keep the rise in global temperatures to $1.5^{\circ} \mathrm{C}$. higher than what it was in the era before industrialisation. We are currently on target for a rise of $3^{\circ} \mathrm{C}$. This risks a 'hothouse' effect in which global temperatures become permanently higher, and where practically nothing can then be done to bring them down (Steffen et al., 2018). Moreover, the last 4 years have already been the warmest on record, leading the World Meteorological Association (2018) to suggest that world temperatures could even rise by between $3^{\circ} \mathrm{C}$ and $5^{\circ} \mathrm{C}$ by 2100 , with catastrophic results.

(c) Cambridge University Press and Australian and New Zealand Academy of Management 2019. 
Ken Parry was most certainly alert to many of these issues, and in his last book, co-authored with Brad Jackson (Jackson \& Parry, 2018), was explicitly critical of the failure of many leadership scholars to confront the flaws of what they termed 'brute capitalism' ( $\mathrm{p} .131$ ) and the tendency to neglect the moral dimensions of much decision making in business. As they noted, "the "leadership for what" question is preoccupying a growing cadre of leadership scholars... Closely related to this question is the "leadership for whom?" which is inextricably bound up with the "leadership by whom" question?' (p. 130).

Following in their footsteps, we can ask: why do most leaders continue to ignore climate change, and why do some who deny it manage to obtain power? What sort of leadership is needed to push the issue up the agenda of governments and business organisations? No wall built around any country or organisation can keep out the climate. People seem to oscillate between apathy and panic when climate change is raised. Both moods lead to paralysis rather than action. Attempts to scare the bejesus out of people haven't worked. But calls to drastically curtail the lifestyle benefits of civilisation are unlikely to work either. As I write these lines, protesters in France are more concerned with the price of petrol than the long-term effects of using fossil fuels. Given that so many of them feel economically disadvantaged, it is hard to blame them. So what will work? Or are we doomed? This is a rich field for leadership scholars to plough, but we seem to walk past mostly in silence. Why?

Ken Parry certainly believed that leadership research and education, properly conceived, could help us to answer these questions, build public trust and make a difference on both a small and grand scale (Jackson \& Parry, 2018). Researchers are often little more than the servants of those with the deepest pockets and the biggest offices. Ken would surely suggest that we should aim higher and do better.

I could raise similar points in relation to the emerging technological changes that are already transforming the world of work, organisation and management. Schwab (2016) has described what is in prospect as 'the fourth industrial revolution'. Frey and Osborne (2013) conducted a detailed analysis of 702 occupations, ranging across such industries as healthcare, transportation, management and education. They concluded that $47 \%$ of total US employment was at risk. It has been suggested that low wage jobs have five times the potential to be mechanised than their higher paid counterparts (Lawrence, Roberts, \& King, 2017).

Of course, this process may be only partial, with aspects of jobs automated and fragments remaining. Nedelkoska and Quintini (2018) looked at 32 of the 35 countries within the Organization for Economic Cooperation and Development (OECD). They concluded that only about $14 \%$ of jobs were 'highly automatable' - that is, there was a $70 \%$ or more probability of automatisation. What seems more likely than the outright disappearance of work is that its nature will change, with many tasks now performed by humans undertaken by machines. The OECD report is also careful to point out that automation will create many new jobs, as it has always done.

This has profound implications for how we see leadership. Firstly, the turmoil that may lie ahead can further polarise the interests of senior leaders and employees. What value is there in talk of rallying people behind a shared vision if that vision consists of getting rid of them? How will theories such as transformational and authentic leadership deal with this? Secondly, if we really are entering into a more mechanised work environment then aspects of leadership decision making will themselves become automated. Already, machines outperform humans in processing data and making complex statistical calculations. They could soon be much more effective in formulating strategies and evaluating risk. Therefore, the managerial cadre may shrink while the human workforce also shrinks. Furthermore, machines don't need motivating, rewards or threats in order to perform. They don't need annual appraisals, away days, inspiring speeches or leadership development. Are our existing leadership theories remotely up to the task of understanding all these issues? And what is the role of leadership in ensuring that whatever technological upheavals lie ahead can be used to benefit the many rather than just those who own shares? Thirdly, the new jobs and professions that will emerge are likely to be occupied by highly skilled and self-motivated professionals. I doubt that the leadership theories and prescriptions 
developed from the study of manufacturing industries in the USA in the 20th century will be of much relevance. But what will be?

\section{The Meaning of Meaningless Theory}

Two problems with our use of theory in leadership research prevent the kind of engagement I am urging here. Firstly, the most dominant paradigm within leadership studies over the past 40 years has undoubtedly been transformational leadership (henceforth, TL) (Bass \& Riggio, 2006). This stresses the role of supposedly heroic individuals in transforming the attitudes, behaviours and emotions of more or less compliant followers. Its appeal to leaders may be obvious. It legitimises the greater concentration of power in their hands, panders to their egos and helps them to justify their huge salaries. The resulting research is largely technocratic rather than interrogative. As Spoelstra, Butler, \& Delaney (2016: 387) point out:

"There is little reflection on ends and means. The concept of "transformation" in transformational leadership or the concept of "ethics" in ethical leadership are rarely debated on the level of fundamentals (e.g. what kind of transformation does transformational leadership refer to? Why are these transformations seen as desirable? What theory of the good is ethical leadership based on?). In other words, instead of questioning the basic theoretical assumptions of such concepts, "critical" debate in mainstream leadership studies tends to focus on the dimensions of a particular construct and its measurement'.

But if we are to seriously engage with the problems that the world faces then it is precisely such questioning that is needed. Ken Parry refused to remain trapped in paradigmatic silos and was never afraid to raise difficult questions. In this case, he would have been the first to point out that cowering before vested interest and hiding behind the study of minor issues makes us part of the problem rather than the solution.

Yet, and to be blunt, the uncritical advocacy of theories such as TL unlocks the doors into the executive suite for those academics who promote it, and offers them the prospect of lucrative consulting contracts. It also provides a pretty good route to publication. All you need to do is to identify some gaps in the existing theory of TL, promise to fill them, and you will most likely be published. Since gaps will always exist this can be the work of a lifetime. It is much easier than challenging the core assumptions that come to dominate any field (Alvesson \& Sandberg, 2011). Nor do we need to address issues that really matter.

Secondly, the priority placed on theory development rather than on real world engagement encourages construct proliferation, even when what is being proposed differs little from what already exists (Borman \& Rowold, 2018). Take the current vogue for authentic leadership, which in my view is simply TL wearing a bad wig and a false beard. As with its TL predecessor, the theory suggests that there are few limits on what powerful - sorry, authentic - leaders can accomplish. They satisfy followers' basic needs (Leroy, Anseel, Gardner, \& Sels, 2015), encourage followers to be more authentic in their own behaviours (Yagil \& Medler-Liraz, 2014) and cause them to display moral courage (Hannah, Avolio, \& Walumbwa, 2011). It is also claimed that they produce superior business results (Walumbwa, Christensen, \& Hailey, 2011). Authentic leaders, it is said, exemplify high-moral standards, integrity and honesty, 'and their favourable reputation fosters positive expectations among employees, enhancing their levels of trust and willingness to cooperate with the leader for the benefit of the organization' (Hsieh \& Wang, 2015: 2341). Such approaches encourage us to become ever more dependent on the wisdom of others rather than think for ourselves. It prevents us from considering how leadership can be reoriented away from the search for a corporate saviour (Khurana, 2002), and towards encouraging more of us to become engaged in the quest to solve big problems.

Thus, instead of making a difference, much of the writing in leadership studies ends up stating the blindingly obvious in the form of convoluted tautologies. Consider hypotheses such as the 
following: 'Authentic leadership behaviour is positively related to follower perceptions of leader behavioural integrity' (Leroy, Palanski, \& Simons, 2012: 257). All this really means is that leaders who behave with integrity are seen as behaving with integrity. This is a circular mode of reasoning, and it pervades our field. It certainly doesn't provide a theoretical framework that helps researchers, organisations and society to grapple with the chronic problems that now confront all of us. I know, not least from personal conversations, that Ken shared these concerns. Surely we can at least try to do better.

\section{The Bias for Positive Results}

The relevance and critical potential of our research is further undermined by methodological problems. Like the wider field of management and organisation studies, leadership studies is biased towards quantitative methodologies and mindsets that favour the publication of only positive results. These encourage such deceptive research practices as $p$-hacking, in which data are poked, prodded and pummelled until they demonstrate statistical significance (Tourish \& Craig, 2018). This is no small matter. Many of us have avoided addressing really important questions so that we can focus on bite-sized studies that lead to relatively rapid publication. But if much of this is invalid or unreliable, what is the point? In my opinion, for example, much of the research on authentic leadership is no longer merely biased in favour of finding positive results. Rather, studies are designed so that only positive results can be discovered (Tourish, 2019).

You think I am exaggerating? Then let me cite a study published in the prestigious Leadership Quarterly (Steffens, Mols, Haslam, \& Okimoto, 2016). The authors gathered data from a final sample of 73 students. They were given a one page article to read on an Australian politician who had switched his support from the then Prime Minister to a challenger. In one version of the article, the headline read: 'Bill Shorten changes his mind to advance personal interests'. The other headline read that 'Bill Shorten changes his mind to advance collective interests'. Subjects in the second condition rated the leader much more highly than those in the first, when their attitudes were measured via the Authentic Leadership Questionnaire. This was interpreted as support for authentic leadership.

Now look more closely. The first headline is a depiction of selfishness and will contaminate any responses that are obtained. Of course, the second headline is also guaranteed to skew responses. An obvious conclusion, surely, is that when people are given negative information about a leader they tend to rate that leader as poor on whatever measurement of leadership that you present them with. On the other hand, when they are given positive information about a leader the opposite will happen. This tells us less than nothing about 'authentic leadership.' But it tells us a great deal about the flawed methods used to study it.

Wood, Phan, and Wright (2018: 405) have produced a compelling critique of how theory is used in the wider management field. They point out that 'Largely because our journals expect it, authors forcefit theory to phenomena that are still emerging'. When theory is deployed prematurely or indiscriminately in this way, as in my example above, key aspects of whatever problem we are exploring can be readily missed. To its profound discredit, this kind of thing is far too common within leadership studies. Researchers set out already convinced that their theory is right and design work that is intended only to confirm it, rather like a stage magician who always makes the right card appear on cue. Such an approach limits our ability to offer solutions for real world problems and to develop genuinely worthwhile theories.

The Nobel prize winning physicist Richard Feynman (1988: 218) once wrote that: 'The only way to have real success in science, the field I'm familiar with, is to describe the evidence very carefully without regard to the way you feel it should be. If you have a theory, you must try to explain what's good about it and what's bad about it equally.' Without this, we have pseudoscience. This may be the current state of much research into leadership.

I think it means that we should be deeply worried about the state of our field. 


\section{What is to be done?}

Researchers need to reaffirm the motivations that brought most of us into academic life in the first place. These include a curiosity about ideas, a love of writing and the desire to make a positive difference to the world in which we live. For many of us, this starting point has been overwhelmed by the audit imperatives that now colonise academia, and the consequent need to keep churning out papers to keep our jobs. Of course, this regulatory environment can't be ignored entirely. But if we let it wholly supplant our sense of intrinsic motivation, and the joy of discovery, then academic life is worse than pointless. It becomes harmful, since it means that we are polluting the publication biosphere with pretentious theories, flawed methods, erroneous conclusions and trivial insights. We need, I think, a greater willingness to address problems that really matter.

As part of this, we need to lose some of our fascination with questionnaire surveys and primitively designed experiments. The world is too complex to be studied only by these means. We need deeper forms of engagement with the organisations that we study, and we need to draw upon multiple sources of data and modes of writing to do so. This also suggests a stronger emphasis on research integrity, and the disavowal of practices that prioritise publication above the disinterested pursuit of truth. Without this, we are little better than snake oil salesmen and have no place within a University environment.

I think we also need to back pedal on our fascination with theory development. Of course, good theory is important. But so is gathering useful data on significant problems, addressing the practical implications of our work, and incidentally writing in accessible language. The insistence by journals that every paper must develop theory, and be shoehorned into the same lifeless template, encourages a great deal of pretentious gibberish. If an existing theory can explain new and fascinating data perfectly well, why should that be a problem? And why should our work be written in such a convulated fashion that it is only accessible to those already on the inside of the debates that we are referencing?

Ken Parry was firmly of the view that leadership is important, and I agree with him. He was passionate about making a difference, constantly open to new ideas, and determined to resist being trapped by rigid methodologies, constraining theoretical frameworks and trivial topics. Personally, I drew inspiration from his ideas on many topics, including the complex and co-constructive relationship between organisational stories and leadership (Parry \& Hansen, 2007), and how leaders attempt to generate attributions of charismatic leadership that followers then more or less willingly bestow on them (Parry \& Kempster, 2013). A spirit of challenge, even contrarianism, runs through much of this work, and we are all the better for it. Channelling his energy, all I can say is that our lives are too short to waste on nonsense, and the mindless pursuit of publication for its own sake.

I last met Ken after his diagnosis, and we spent a hugely enjoyable couple of hours having lunch while debating the travails of University life and, of course, the meaning of the Universe, life, death and everything in between. It was not a morbid occasion. Rather than pre-live death, Ken was determined to enjoy whatever time he had left to the full. His unfailing sense of humour and mischief remains a delightful memory. As we left our lunch venue Ken spotted a fellow New Zealander wearing an All Blacks t-shirt, and couldn't resist stopping to share his hopes for an upcoming and no doubt vital game of rugby. In honouring his life and work, let us resolve to make the most of whatever talents we are lucky enough to possess, for however long we have them.

Let's take Ken's lead, and make a difference.

Author ORCIDs. (D) Dennis Tourish, 0000-0002-9881-1930.

\section{References}

Alvesson, M., \& Sandberg, J. (2011). Generating research questions through problematization. Academy of Management Review, 36, 247-271.

Bass, B., \& Riggio, R. (2006). Transformational leadership (2nd ed.). Mahwah, NJ: Lawrence Erlbaum. 
Borman, K., \& Rowold, J. (2018). Construct proliferation in leadership style research: Reviewing pro and contra arguments. Organizational Psychology Review, 8, 149-173.

Feynman, R. (1988). "What do you care what other people think?" Further adventures of a curious character. New York: W. Norton.

Frey, C., \& Osborne, M. (2013). The future of employment: How susceptible are jobs to computerization? Oxford Martin Programme on Technology and Employment, Oxford: Oxford University.

Hannah, S., Avolio, B., \& Walumbwa, F. (2011). Relationships between authentic leadership, moral courage, and ethical and prosocial behaviors. Business Ethics Quarterly, 21, 555-578.

Hsieh, C., \& Wang, D. (2015). Does supervisor perceived authentic leadership influence employee work engagement through employee- perceived authentic leadership and employee trust? The International Journal of Human Resource Management, 26, 2329-2348.

Jackson, B., \& Parry, K. (2018). A very short, fairly interesting and reasonably cheap book about studying Leadership (3rd ed.). London: Sage.

Khurana, R. (2002). Searching for a corporate savior: The irrational quest for charismatic CEOs. Princeton: Princeton University Press.

Lawrence, M., Roberts, C., \& King, L. (2017). Managing automation: Employment, inequality and ethics in the digital Age. London: The IPPR Commission on Economic Justice.

Leroy, H., Anseel, F., Gardner, W., \& Sels, L. (2015). Authentic leadership, authentic followership, basic need satisfaction, and work-role performance: Across-level study. Journal of Management, 41, 1677-1697.

Leroy, H., Palanski, M., \& Simons, T. (2012). Authentic leadership and behavioural integrity as drivers of follower commitment and performance. Journal of Business Ethics, 107, 255-264.

Nedelkoska, L., \& Quintini, G. (2018). Automation, skills use and training, Organization for Economic Co-operation and Development. Retrieved April 16, 2018, from https:/www.oecd-ilibrary.org/docserver/2e2f4eea-en.pdf?expires=1523873145 \&id=id\&accname=guest\&checksum=BA4E0D2082E128FE4FABFEC1FF5B3CB2

Parry, K., \& Hansen, H. (2007). The organizational story as leadership. Leadership, 3, 281-300.

Parry, K., \& Kempster, S. (2013). Love and leadership: Constructing follower narrative identities of charismatic leadership. Management Learning, 45, 21-38.

Schwab, K. (2016). The fourth industrial revolution. Geneva: World Economic Forum.

Spoelstra, S., Butler, N., \& Delaney, H. (2016). Never let an academic crisis go to waste: Leadership studies in the wake of journal retractions. Leadership, 12, 383-397.

Steffen, W., Rockström, J., Richardson, K., Lenton, T., Folke, C., Liverman, D., ... Schellnhuber, H. (2018, August 14). Trajectories of the earth system in the Anthropocene. PNAS, 115(33), 8252-8259; published ahead of print August 6, 2018. From https://doi.org/10.1073/pnas.1810141115

Steffens, N., Mols, F., Haslam, A., \& Okimoto, T. (2016). True to what we stand for: Championing collective interests as a path to authentic leadership. The Leadership Quarterly, 27, 726-744.

Tourish, D. (2019). Management studies in crisis: Fraud, deception and meaningless research. Cambridge: Cambridge University Press.

Tourish, D., \& Craig, R. (2018). Research misconduct in business and management studies: Theorising its causes, exploring its consequences and possible remedies. Journal of Management Inquiry. doi: 10.1177/1056492618792621.

United Nations Intergovernmental Panel on Climate Change. (2018). Retrieved December 1, 2018, from https://www.ipcc.ch/ pdf/special-reports/sr15/sr15_ts.pdf

Walumbwa, F., Christensen, A., \& Hailey, F. (2011). Authentic leadership and the knowledge economy: Sustaining motivation and trust among knowledge workers. Organizational Dynamics, 40, 110-118.

Wood, G., Phan, P., \& Wright, M. (2018). The problems with theory and new challenges in theorizing. Academy of Management Perspectives, 32, 405-411.

World Meteorological Association. (2018). Retrieved December 2, 2018, from https://public.wmo.int/en/media/press-release/ climate-change-signals-and-impacts-continue-2018

Yagil, D., \& Medler-Liraz, H. (2014). Feel free, be yourself: Authentic leadership, emotional expression, and employee authenticity. Journal of Leadership and Organizational Studies, 21, 59-70.

Cite this article: Tourish D (2019). Making a difference: Doing leadership research that matters. Journal of Management \& Organization 25, 364-369. https://doi.org/10.1017/jmo.2019.6 